\title{
Duplicate publication
}

The Meeting of Anesthesiology Journal Publishers, held during the World Congress of the specialty in 2000, discussed a problem that concerned them: authors who sent to two or more magazines the same work. At that time, communication was restricted and it was often difficult to detect this unethical practice.

What are the strategies to curb them?

In the end it was agreed on the desirability of the editors of leading journals in Anesthesiology to maintain communication with each other so that when they got to works by authors known for this practice, they exchanged correspondence in an attempt to prevent the same work from being published in more than one magazine.

At this moment the Revista Brasileira de Anestesiologia (RBA) was applying for its indexation in the National Library and, therefore, was invited to the meeting. I have attended representing the Editor-in-chief, acting as Co-editor.

Soon after, the indexing was denied and the Revista Brasileira de Anestesiologia was no longer invited to meetings in subsequent congresses.

After 11 years, already indexed, the RBA now faces this problem as a victim of this practice.

The pressures to publish affect all research groups around the world. Last year during the European Congress of Anesthesiology, at an event attended by many journal editors and members of editorial boards, the low quality of scientific work influenced by the need to achieve goals of publication was discussed, matter of difficulty even in traditional research centers.

The Ministry of Education, through CAPES, when classifying the majority of Brazilian health journals in lower categories, certainly did not collaborate on the development, qualification and maintenance of titles of the Supervising Professors of Post-graduation Programs. Moreover, this threatened the survival of national journals that are set aside, albeit unintentionally, by some very productive Brazilian researchers, because inbreeding is considered a failure, and there is stimulus to submit the best work for journals best classified by CAPES, which are not national. It is so created the vicious circle in search of greater impact.

The problem exposed by the Editor-in-chief of the Revista Brasileira de Anestesiologia is unfortunately not unprecedented and strikes the seriousness of research in Brazil. As always the attitude of a few touches everyone, and hard work of many can be shaken.

It is in defense of serious, continuous, ethical, and more exuberant research in Brazil that I write this editorial. It is not by circumventing that one gets respect. It is not through lying that evidences are built. This is not the way of teaching the ones that are now beginning in Science. Our responsibility to educate by example never runs out and repudiation of this practice should be verbalized, written and published in every way possible, so that Brazilian researches are not globalizedin their evil side, joining the worldwide list of supporters of the simultaneous publication.

I leave here my support to the Editor-in-chief, who realized the occurrence and took all reasonable attitudes to exempt all other groups publishing in the Revista Brasileira de Anestesiologia of seeing their efforts contaminated. I am sure that the Brazilian scientific community is not complacent about this practice, which could destabilize the credibility of all.

Judymara Lauzi Gozzani Associate Editor 